\title{
ЭКОНОМИКА
}

ECONOMICS

Булавенко О. А., Василенко А. В.

O. A. Bulavenko, A. V. Vasilenko

СРАВНИТЕЛЬНЫЙ АНАЛИЗ ПОТРЕБИТЕЛЬСКИХ КРЕДИТОВ

\section{THE COMPARATIVE ANALYSIS OF CONSUMER LOANS}

Булавенко Олег Анатольевич - доктор экономических наук, профессор, заведующий кафедрой сервиса и торгового дела Комсомольского-на-Амуре государственного технического университета (Россия, Комсомольск-на-Амуре). E-mail: o-bul@yandex.ru.

Mr. Oleg A. Bulavenko - Doctor of economic sciences, professor, head of the service and trade business department, Komsomolsk-on-Amur State Technical University (Russia, Komsomolsk-on-Amur). E-mail: o-bul@yandex.ru.

Василенко Анна Владимировна - студентка магистратуры 1-го курса факультета экономики и менеджмента направления «Торговое дело» Комсомольского-на-Амуре государственного технического университета (Россия, Комсомольск-на-Амуре). E-mail: ann_love_summer@mail.ru.

Ms. Anna V. Vasilenko - Master's Degree Student of the first year major in Trade business, faculty of economics and management, Komsomolsk-on-Amur State Technical University (Russia, Komsomolsk-on-Amur). E-mail: ann_love_summer@mail.ru.

Аннотация. В данной статье дано определение потребительских кредитов, их классификация и сравнительный анализ трех видов потребительских кредитов.

Summary. In this article definition to consumer loans is given, their classification and the comparative analysis of three types of consumer loans are presented.

Ключевые слова: потребительский кредит, классификация потребительских кредитов, базовые условия, потребительский кредит без обеспечения, потребительский кредит под поручительство физических лиц, потребительский кредит на рефинансирование кредитов.

Key words: consumer loan, classification of consumer loans, basic conditions, uncovered consumer loan, a consumer loan under the guarantee of individuals, a consumer loan for refinancing of the credits.

УДК 336.77

В банковской сфере наиболее востребованным продуктом для населения является потребительский кредит, ведь именно потребительский кредит позволяет приобрести товар или услугу в момент ее наивысшей актуальности для потребителя. Банковская деятельность является очень чувствительной как к разным факторам социально-экономического характера, так и к политическим, экологическим и прочим факторам, иными словами, банк несет весь спектр банковских рисков. Для наиболее качественного предоставления услуг населению и наибольшей минимизации рисков изначально необходимо ознакомиться с классификацией потребительских кредитов и их базовыми условиями.

Потребительский кредит - форма общественных отношений, возникающая между физическими лицами - заемщиками и кредитными учреждениями - кредиторами для приобретения предметов потребления.

Классификация потребительских кредитов представлена на рис. 1.

В зависимости от целей кредиты могут оформляться на покупку определенных отваров (в таком случае кредит может носить неденежную форму) и тратиться на усмотрение заемщика. Кредиты с обеспечением выдаются под залог имущества или под поручительство. 







\begin{tabular}{|c|c|c|c|}
\hline & & & Продолжение табл. 1 \\
\hline 1 & 2 & 3 & 4 \\
\hline $\begin{array}{l}\text { Максимальный } \\
\text { срок }\end{array}$ & 60 месяцев & 60 месяцев & $\begin{array}{l}60 \text { месяцев } \\
\text { Если заемщиком в составе Пакета документов не } \\
\text { предоставлены документы, подтверждающие его } \\
\text { финансовое состояние и трудовую занятость, а также } \\
\text { не предоставлена информация о номере зарплатной } \\
\text { карты/вклада в Банке, максимальный срок кредито- } \\
\text { вания должен быть равен: } \\
\text { - сроку в целых месяцах до полного планового пога- } \\
\text { шения рефинансируемого кредита в соответствии с } \\
\text { кредитным договором со дня принятия решения о } \\
\text { возможности предоставления кредита; } \\
\text { - сроку в целых месяцах до полного планового пога- } \\
\text { шения рефинансируемого кредита в соответствии с } \\
\text { кредитным договором со дня принятия решения о } \\
\text { возможности предоставления кредита, по которому } \\
\text { данное значение максимально - при рефинансирова- } \\
\text { нии более одного кредита; } \\
\text { - в случае рефинансирования задолженности по кре- } \\
\text { дитной карте и дебетовой банковской карте с разре- } \\
\text { шенным овердрафтом срок до полного планового } \\
\text { погашения рефинансируемого кредита принимается } \\
\text { равным } 36 \text { месяцам с даты приема полного Пакета } \\
\text { документов }\end{array}$ \\
\hline $\begin{array}{l}\text { Минимальный } \\
\text { размер кредита }\end{array}$ & $\begin{array}{l}15000 \\
\text { рублей }\end{array}$ & $\begin{array}{l}15000 \\
\text { рублей }\end{array}$ & $\begin{array}{l}15000 \text { рублей (но не менее остатка задолженности } \\
\text { по рефинансируемому кредиту) }\end{array}$ \\
\hline $\begin{array}{l}\text { Максимальный } \\
\text { размер кредита }\end{array}$ & $\begin{array}{l}1500000 \\
\text { рублей }\end{array}$ & $\begin{array}{l}3000000 \\
\text { рублей }\end{array}$ & $\begin{array}{l}1000000 \text { рублей } \\
\text { Если заемщиком в составе Пакета документов не } \\
\text { предоставлены документы, подтверждающие его } \\
\text { финансовое состояние и трудовую занятость, а } \\
\text { также не предоставлена информация о номере зар- } \\
\text { платной карты/вклада в Банке, максимальный срок } \\
\text { кредитования должен быть равен: } \\
\text { 1) остатку ссудной задолженности и начисленных } \\
\text { процентов по рефинансируемому кредиту; } \\
\text { 2) остатку ссудной задолженности и начисленных } \\
\text { процентов по рефинансируемому кредиту, выдан- } \\
\text { ному Банком, увеличенному на сумму процентов за } \\
31 \text { день пользования Первичным кредитором. } \\
\text { Но не более максимального размера кредита по } \\
\text { продукту }\end{array}$ \\
\hline $\begin{array}{l}\text { Порядок } \\
\text { погашения }\end{array}$ & \multicolumn{3}{|c|}{$\begin{array}{l}\text { Ежемесячно аннуитетными платежами перечислением со счета (по вкладу или бан- } \\
\text { ковской карте) в день, соответствующий дню фактического предоставления кредита, } \\
\text { начиная с месяца, следующего за месяцем фактического предоставления кредита }\end{array}$} \\
\hline $\begin{array}{l}\text { Досрочное } \\
\text { погашение }\end{array}$ & \multicolumn{3}{|c|}{$\begin{array}{l}\text { Осуществляется без предварительного уведомления Банка по заявлению, содержа- } \\
\text { щему дату досрочного погашения, сумму и счет списания денежных средств. Дата } \\
\text { досрочного погашения должна приходиться исключительно на рабочий день }\end{array}$} \\
\hline $\begin{array}{l}\text { Возможность } \\
\text { предоставления } \\
\text { отсрочки погаше- } \\
\text { ния кредита }\end{array}$ & $\begin{array}{l}\text { Не преду- } \\
\text { смотрено }\end{array}$ & $\begin{array}{l}\text { Не преду- } \\
\text { смотрено }\end{array}$ & Не предусмотрено \\
\hline
\end{tabular}




\begin{tabular}{|c|c|c|c|}
\hline \multirow[t]{2}{*}{ (2) } & \multicolumn{2}{|c|}{ 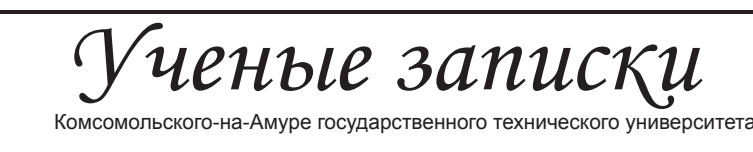 } & Neта \\
\hline & \multicolumn{3}{|r|}{ Окончание табл. 1} \\
\hline 1 & 2 & 3 & 4 \\
\hline $\begin{array}{l}\text { Наличие созаем- } \\
\text { щиков }\end{array}$ & Не предусмотрено & \begin{tabular}{|c|} 
Предусмотрено, но не \\
является обязательным
\end{tabular} & Не предусмотрено \\
\hline $\begin{array}{l}\text { Требования к за- } \\
\text { емщику/ } \\
\text { созаемщику }\end{array}$ & \multicolumn{3}{|c|}{$\begin{array}{l}\text { Возраст - от } 21 \text { года до } 65 \text { лет. Физическим лицам, являющимися судьями, кредит } \\
\text { предоставляется до } 70 \text { лет } \\
\text { Регистрация по месту жительства - обязательная (постоянная или временная) } \\
\text { Трудовой стаж на текущем месте работы - не менее 3-х месяцев на дату предо- } \\
\text { ставления Пакета документов в Банк }\end{array}$} \\
\hline Обеспечение & Не требуется & $\begin{array}{c}\text { Поручительства } \\
\text { платежеспособных } \\
\text { физических лиц }\end{array}$ & Не требуется \\
\hline $\begin{array}{l}\text { Порядок подтвер- } \\
\text { ждения целевого } \\
\text { использования } \\
\text { кредита }\end{array}$ & Не предусмотрено & Не предусмотрено & $\begin{array}{l}\text { В течение } 45 \text { суток с даты заключения } \\
\text { Кредитного договора должны быть } \\
\text { представлены заверенные печатью и } \\
\text { подписью уполномоченного работника } \\
\text { Первичного кредитора справка /выписка } \\
\text { об отсутствии задолженности по рефи- } \\
\text { нансируемому кредиту }\end{array}$ \\
\hline $\begin{array}{l}\text { Срок рассмотрения } \\
\text { кредитной заявки }\end{array}$ & $\begin{array}{l}\text { Не более 2-х } \\
\text { рабочих дней }\end{array}$ & $\begin{array}{l}\text { Не более 2-х } \\
\text { рабочих дней }\end{array}$ & Не более 2 -х рабочих дней \\
\hline \multicolumn{4}{|c|}{$\begin{array}{l}\text { Итак, у данных продуктов установлены различия: в целевом назначении и наличии целе- } \\
\text { вого подтверждения, максимальной сумме кредита, максимальном сроке предоставления кредита } \\
\text { и наличии обеспечения. Но такие показатели как валюта, минимальный размер кредита, макси- } \\
\text { мальный срок кредита, условия предоставления кредита и срок рассмотрения заявки на кредит у } \\
\text { данных продуктов являются одинаковыми. } \\
\text { Таким образом, потребительский кредит является наиболее актуальным продуктом, пред- } \\
\text { лагаемым на рынке, который позволяет не только приобретать необходимые товары, но и на более } \\
\text { выгодных условиях рефинансировать действующий кредит, полученный у Первичного кредитора. } \\
\text { Для более качественного консультирования клиентов и составлении заявки на кредит используют- } \\
\text { ся базовые условия предоставления кредита, которые также были изложены и сведены в табл. } 1 . \\
\text { лиТЕРАТУРА } \\
\text { 1. Банковское дело: современная система кредитования: учеб. пособие / под ред. засл. деят. науки РФ, д-ра } \\
\text { экон. наук, проф. О. И. Лаврушина. - М.: КНОРУС, 2010. - 256 с. } \\
\text { 2. Ключников, И. К. Кредит и банки: вводный курс: учеб.-метод. пособие / И. К. Ключников, О. А. Молча- } \\
\text { нова, О. И. Ключников. - М.: Финансы и статистика, 2007. - } 176 \text { с. }\end{array}$} \\
\hline
\end{tabular}

